\title{
Lawrence Livermore National Laboratory Response to the Federal Communications Commission Notice of Proposed Rulemaking
}

\author{
E. T. Rosenbury, F. U. Dowla
}

\section{August 2000}






\section{DISCLAIMER}

This document was prepared as an account of work sponsored by an agency of the United States Government. Neither the United States Government nor the University of California nor any of their employees, makes any warranty, express or implied, or assumes any legal liability or responsibility for the accuracy, completeness, or usefulness of any information, apparatus, product, or process disclosed, or represents that its use would not infringe privately owned rights. Reference herein to any specific commercial product, process, or service by trade name, trademark, manufacturer, or otherwise, does not necessarily constitute or imply its endorsement, recommendation, or favoring by the United States Government or the University of California. The views and opinions of authors expressed herein do not necessarily state or reflect those of the United States Government or the University of California, and shall not be used for advertising or product endorsement purposes.

This is a preprint of a paper intended for publication in a journal or proceedings. Since changes may be made before publication, this preprint is made available with the understanding that it will not be cited or reproduced without the permission of the author.

This report has been reproduced directly from the best available copy.

Available electronically at http://www.doc.gov/bridge

Available for a processing fee to U.S. Department of Energy

And its contractors in paper from

U.S. Department of Energy

Office of Scientific and Technical Information

P.O. Box 62

Oak Ridge, TN 37831-0062

Telephone: (865) 576-8401

Facsimile: (865) 576-5728

E-mail: reports@adonis.osti.gov

Available for the sale to the public from

U.S. Department of Commerce

National Technical Information Service

5285 Port Royal Road

Springfield, VA 22161

Telephone: (800) 553-6847

Facsimile: (703) 605-6900

E-mail: orders@ntis.fedworld.gov

Online ordering: http:/ / www.ntis.gov/ordering.htm

\section{OR}

Lawrence Livermore National Laboratory

Technical Information Department's Digital Library

http: / / www.llnl.gov/tid/Library.html 


\section{Executive Summary}

Lawrence Livermore National Laboratory (LLNL) has been conducting UWB research for the past few decades and submits a general comments section and a paragraph by paragraph response for consideration. In general, the proposed rules look very sound and encouraging for promoting use of the spectrum by both government and commercial users. General comments include recommending minimum frequency spreading specification, possibly clarifying the peak power limits and keeping the high frequency limit as high as possible. LLNL finds that minimum interference occurs by keeping wideband wide and narrowband narrow and keeping the middle ground clear. 


\section{General Discussion}

As shown in Figure 1, there is a time-frequency duality relationship between the representations of UWB pulses and narrowband signals. Short-duration UWB pulses have some inherent properties that are highly desirable in multiple access RF communication systems: the frequency diversity of the short pulses makes these systems robust with respect to multipath; and short temporal duty cycle allows for low-power and high-capacity multple-access systems. We briefly summarize these properties in the following with illustrations.
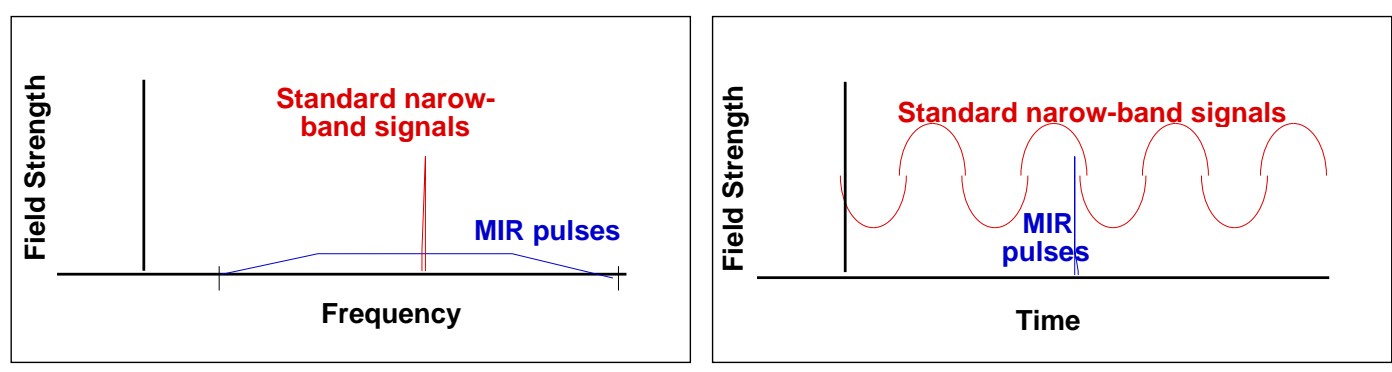

Figure 1: Wideband pulse vs narrowband sinewaves. 


\section{Interference Effects}

In communications, interference from other users is an important problem that must be overcome. Due to the wideband nature of UWB pulses, UWB systems are in many ways less interfering than narrowband systems. This is illustrated in Figure 2.

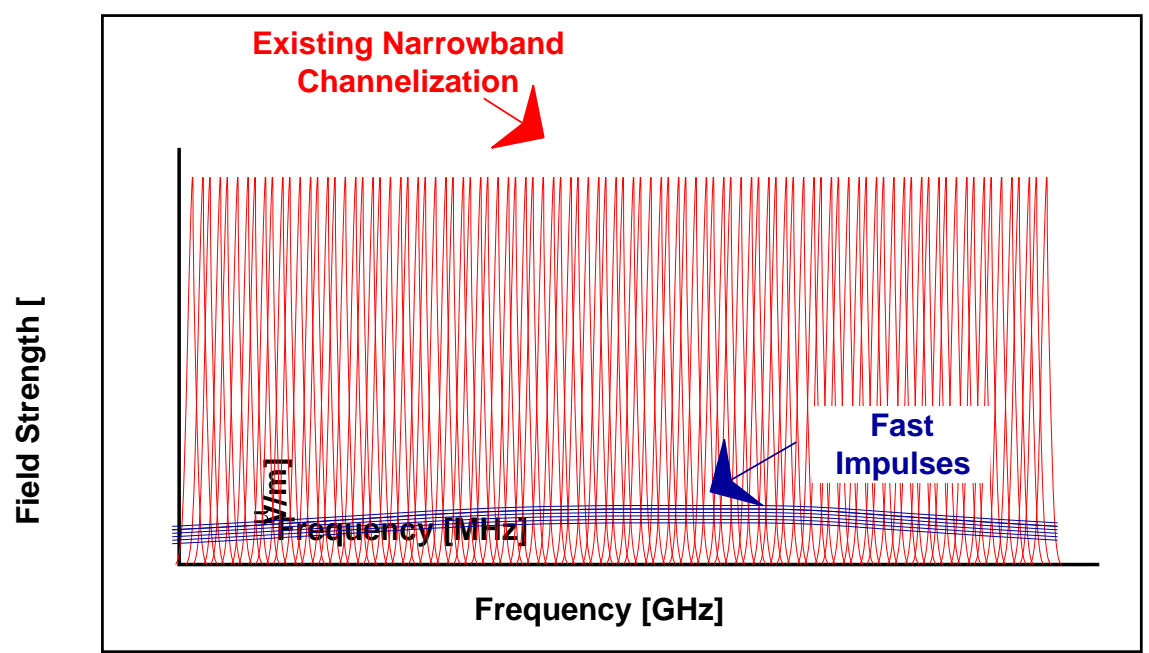

Figure 2: Wideband pulses add very little noise to each (narrow) band.

As shown in Figure 2, the lower power spectral density level of UWB pulses are generally not a significant source of interference on higher power narrowband spectra. This will generally be true as long as narrowband operations are kept narrow, and wideband operations are kept wide in the spectral domain. 


\section{Spectral Efficiency and Cost}

With respect to valuable resources such as bandwidth and power, UWB systems seem to have a significant advantage.

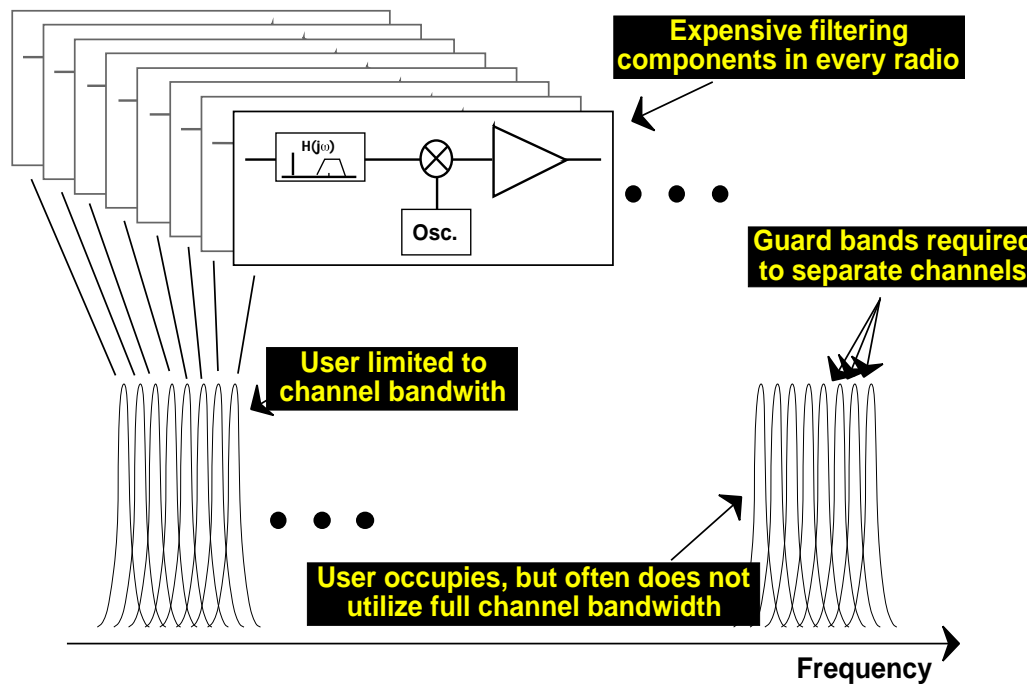

Figure 3: Narrowband communication systems

In Figure 3 we illustrate two of the important reasons why UWB systems might have an advantage both in terms of higher spectral efficiency and lower cost. This is seen by noting that guard bands in narrow band communication systems is a waste of valuable spectral frequencies, and the use of expensive bandpass filters and similar functions make narrowband devices expensive. 


\section{Multiple Access}

As depicted in Figure 4, because the signal strength drops rapidly both as a function of distance and with increasing frequencies, background interference power from a set of multiple UWB radios do not add linearly: the range factor is significant in determining the cumulative effect from multiple transmitters.

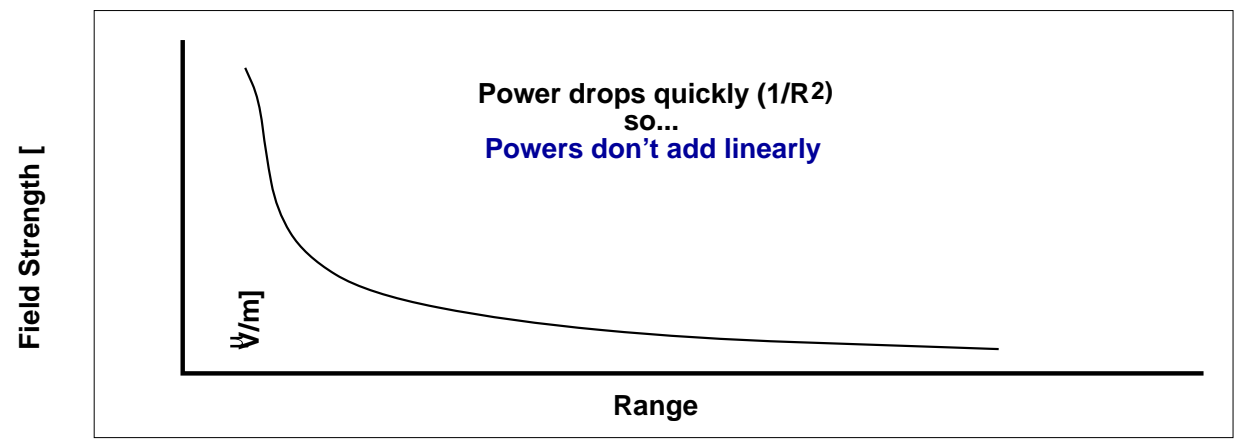

Figure 4: Wideband pulses do not add (linearly). Closest radiator is stronger than the sum of many farther radiators

Studies have also shown that interference is really dominated by average power spectral density levels. The low power spectral density (PSD) levels of UWB pulses allow for many transmitters to coexist before cumulative PSD level becomes significant. (Conversely, in the time domain, two or more UWB pulses would add when they occur exactly at the same time. Statistically this is unlikely because of the short duration nature of these signals.) On the other hand, (see Figure 5), the high PSD levels of narrow band signals can quickly add up to intolerable levels. So the scheme of increasing capacity by "frequency reuse" is really optimized in UWB systems. 


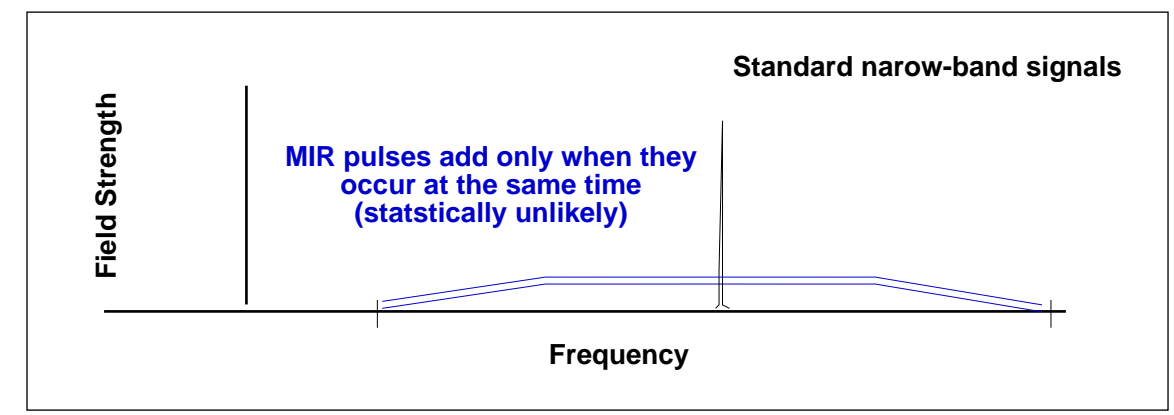

Figure 5: Studies have shown that average power dominates interference. Statistics work in favor of UWB.

\section{Form Factor or Size of Systems}

One of significant practical advantages of UWB systems is their small size. The electronics used in UWB systems are both low cost and small. Our group has built several UWB radar and communication units (see Figure 6) that demonstrates this fact.

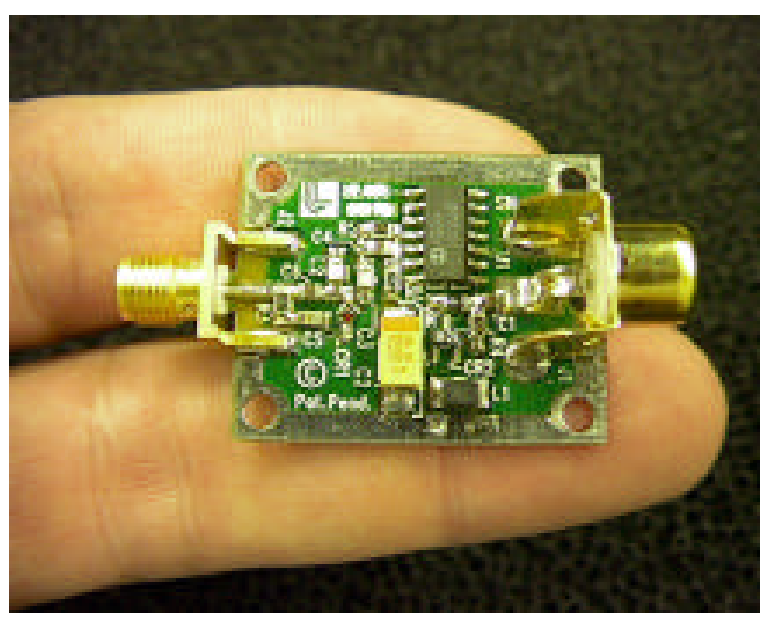

Figure 6: UWB circuitry can be much simpler and cheaper than narrowband circuits. 


\section{Multipath Effects}

Perhaps one of the most significant strengths of UWB communications systems lies with the fact that these signals very good properties with respect to multipath fading.

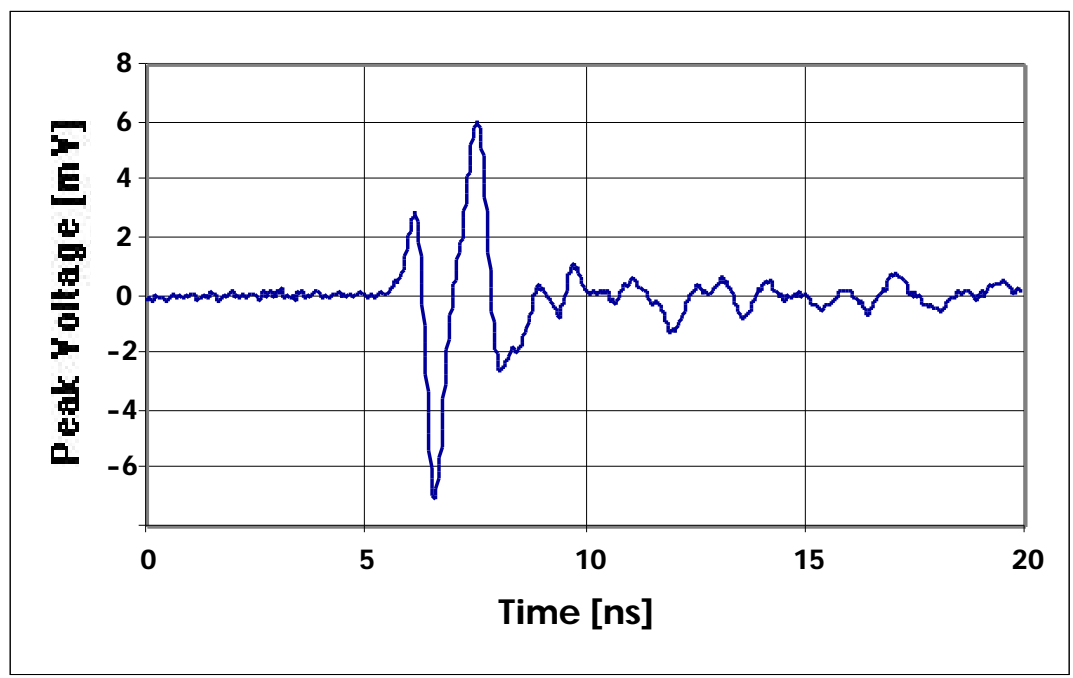

Figure 7: Measured pulse characteristic at receiver.

Although a measured UWB pulse will be somewhat distored after it propagates through a harsh RF environment (see Figure 7), the frequency diversity in these signals makes them very useful in terms of resistance to multipath fading. At LLNL we performed extensive experiments in a large room full of metal racks to understand fading properties as a function of three dimensionsal location of the receiver with respect to an UWB transmitter. These results are summarized in Figure 8. The fading properties of UWB signals as a function of the receiver height, as shown in Figure 8, clearly indicate that the UWB link is much better than a corresponding narrowband link in the same envornment. While there was little or no fading in the UWB signals, narrowband propagation showed fades as large as $30 \mathrm{~dB}$. 




Figure 8 : UWB (impulse) has much less fading (nulls) due to multipath than narrowband. 


\section{Narrowband isolation vs pulse width and UWB bandwidth}

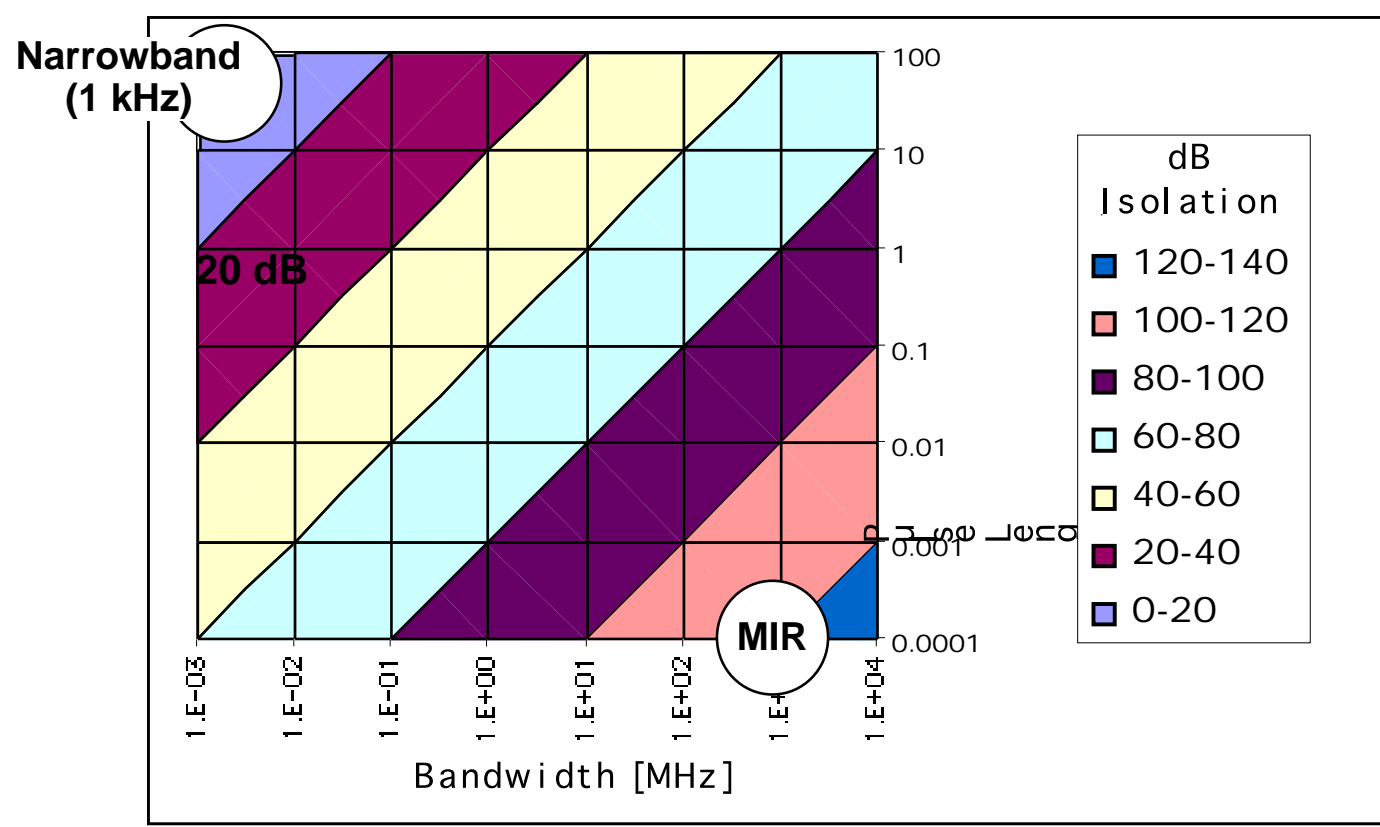

Figure 9: Interference can be quickly estimated from chart. 
Before the

Federal Communications Commission

Washington, D.C. 20554

In the Matter of

\section{)}

Revision of Part 15 of the Commission's Rules

Regarding Ultra-Wideband Transmission ） ET Docket 98-153

Systems

)

\section{NOTICE OF PROPOSED RULE MAKING}

Adopted: May 10, 2000

Released: May 11, 2000

Comment date: [insert date 90 days from publication in Federal Register]

Reply comment date: [insert date 120 days from publication in Federal Register] 
By the Commission:

\section{SUMMARY}

1. By this Notice of Proposed Rule Making ("Notice"), we propose to amend Part 15 of the Commission's rules to pave the way for new types of products incorporating ultra-wideband ("UWB") technology. UWB devices may have the capability to provide for significant benefits for public safety, businesses and consumers. While comprehensive tests have not been completed, UWB devices appear to be able to operate on spectrum already occupied by existing radio services without causing interference, which would permit scarce spectrum resources to be used more efficiently. We are moving forward with this Notice to begin the process of identifying potential rule changes and alternatives necessary for the deployment of UWB technology. The proposals in this Notice are designed to ensure that existing and planned radio services, particularly safety services, are adequately protected. UWB technology is relatively new. Further testing and analysis is needed before the risks of interference are completely understood. Such testing is already being planned by a number of organizations. We will provide ample opportunity to complete these tests and ensure that analyses of the test results are submitted in the record for public comment before adopting any final rules in this proceeding. We invite broad comment on this Notice so that the Commission may ultimately provide for the introduction of this new and exciting technology.

\section{BACKGROUND}

2. The Commission, on its own motion, issued a Notice of Inquiry ("NOI") in this proceeding to investigate the possibility of permitting the operation of UWB devices on an unlicensed basis under Part 15 of the FCC rules. Part 15 of the Commission's regulations permits the operation of RF devices without a license from the Commission or the need for frequency coordination. The technical standards contained in Part 15 are designed to ensure that there is a low probability that these devices will cause harmful interference to other users of the radio spectrum. Intentional radiators, i.e., transmitters, are permitted to operate under a set of general emission limits or under provisions that allow higher emission levels in certain frequency bands. Intentional radiators generally are not permitted to operate in certain sensitive or safety-related frequency bands, designated as restricted bands, or in the frequency bands allocated for television ("TV") broadcasting.

3. The NOI observed that recent advances have enabled the development of UWB technology for a variety of applications. UWB devices can be used for precise measurement of distances or locations and for obtaining the images of objects buried under ground or behind surfaces. UWB devices can also be used for wireless communications, particularly for short-range high-speed data transmissions suitable for broadband access to the Internet. UWB radio systems typically employ pulse modulation whereby extremely narrow pulses are modulated and emitted to convey or receive information. The emission bandwidths generally exceed one gigahertz. In some cases, "impulse" transmitters are employed where the pulses do not modulate a carrier. Instead, the radio frequency emissions generated by the pulses are applied to an antenna, the resonant frequency of which determines the center frequency of the radiated emission. The bandwidth characteristics of the antenna will act as a low-pass filter, further affecting the shape of the radiated signal.

4. The NOI observed that the current Part 15 rules pose two primary obstacles to the implementation of UWB technology. First, the wide bandwidth that is intrinsic to the operation of UWB devices can result in transmission of the fundamental emission into restricted frequency bands or into the television ("TV") broadcast frequency bands, which is prohibited under the Part 15 rules. Second, the current emission measurement procedures specified in our Part 15 rules were developed for narrowband systems and may be inappropriate for, and pose unnecessary restrictions to, UWB technology, particularly impulse systems. For example, Part 15 measurement procedures require the application of a pulse desensitization correction factor. The application of this correction factor can cause UWB systems to exceed the peak emission limits currently specified under the Part 15 rules.

5. The NOI requested comment on the potential applications for UWB devices and their technical characteristics, such as frequency ranges of operation, bandwidths, power levels, and operating distances. In addition, the NOI requested comments concerning what regulatory treatment would be most appropriate for UWB devices, including whether they should be regulated under Part 15 or some other rule part. The $\mathrm{NOI}$ asked how the Commission should define UWB devices. Further, the NOI sought comments on 
whether UWB devices should be prohibited from operating in the restricted frequency bands and TV broadcast frequency bands or if there are certain restricted frequency bands where the Commission should permit UWB operation. Comments were sought concerning what emission limits and measurement procedures would be appropriate for UWB devices. The NOI invited comments on any other matters or issues that may be pertinent to the operation of UWB systems. In response to the NOI, 42 parties filed comments and 37 parties filed reply comments. The list of the commenting parties is shown in Appendix $B$. 6. In the NOI the Commission noted that three requests for waivers of the Part 15 rules were filed to permit the operation of UWB systems. U.S. Radar Inc. filed a Petition for Waiver to permit the operation of a ground penetrating radar system that could be used to detect buried objects. Time Domain Corp. filed a Petition for Waiver to permit systems that would be used by public safety personnel for high resolution imaging of persons and objects behind walls or under debris. Zircon Corporation also filed a Request for Waiver to permit radar systems that would be used by the construction industry to detect objects hidden inside walls or other building materials. Because the waiver requests included frequency bands allocated to the U.S. Government, they were coordinated closely with the National Telecommunications and Information Administration (NTIA). The three waiver requests were granted on June 25, 1999 by the Chief of the Office of Engineering and Technology, based on a number of technical and other conditions requested by NTIA to protect against interference to radio services.

\section{DISCUSSION}

7. We have thoroughly reviewed all of the comments and reply comments filed in this proceeding. Based on this review, we believe that UWB devices may offer significant benefits for public safety, businesses and consumers, as discussed in detail below. Further, we observe that most UWB devices cannot operate under our current regulations. Therefore, we tentatively conclude that the Commission's rules should be amended to provide for UWB devices. At the same time, we recognize that any new rule provisions for UWB devices must ensure that radio services are protected against interference. Many of the comments suggested that further testing and analysis is needed before the potential for interference is fully understood, particularly potential interference to safety services such as the Global Positioning System (GPS). We note that the NTIA, the U.S. Department of Transportation, and other organizations are planning such tests. We plan to allow a reasonable period of time for submittal of test results into the record in this proceeding and will provide an opportunity for public comment on the test results before reaching any conclusions. However, we believe it is appropriate at this juncture to issue a Notice of Proposed Rule Making to begin the process of identifying possible rule amendments and alternatives. This Notice provides an important framework for considering the various technical issues. We invite broad comment on these issues.

\section{Applications and General Characteristics}

8. We believe that UWB technology holds promise for a vast array of new or improved devices that could have enormous benefits for public safety, consumers and businesses. Further, we anticipate the UWB technology could create new business opportunities for manufacturers, distributors and vendors that will enhance competition and the economy. UWB technology may also enable increased use of scarce spectrum resources by sharing frequencies with other services without causing interference. It is important that we find ways to encourage the development and deployment of technologies that may allow more efficient use of the spectrum. We note that Section 7 of the Communications Act of 1934, as amended, requires the Commission "to encourage the provision of new technologies and services to the public." Accordingly, we conclude that the Commission should develop reasonable regulations that will foster the development of UWB technology while continuing to protect radio services against interference.

9. The NOI invited comment on the potential applications and general technical characteristics for UWB technology, noting that UWB systems appeared to fall into two categories: systems that use radar techniques for precise measurements of distance, and detection or imaging of objects; and communications systems that can be used for voice, data and control signals.

\section{Radar Applications}

10. The comments described a wide assortment of existing and potential applications for UWB technology that employ radar principles. Several parties note that UWB technology has been in use for some time for ground penetrating radar ("GPR") applications. GPR devices are used for purposes such as: determining the structural soundness of bridges, roadways, and airport runways; locating buried containers that may 
contain hazardous wastes; determining the location of underground utilities, such as natural gas, electricity, water and sewage lines, irrespective of the composition of the piping or conduit; geologic surveys; archeological digs; and, law enforcement and forensic investigations. The comments stated that UWB technology is being developed for new types of imaging systems that would enable police, fire and rescue personnel to locate persons hidden behind a wall or under debris in situations such as hostage rescues, fires, collapsed buildings, or avalanches. Imaging devices also could be used to improve the safety of persons in the construction and home repair industries by allowing individuals to locate steel reinforcement bars (i.e., re-bar) in concrete, or wall studs, electrical wiring and pipes hidden inside walls.

11. Numerous other applications for UWB technology using radar techniques were brought to our attention. Potential automotive uses include forward-looking and lane change collision avoidance systems, backup warning systems, air bag proximity measurement for safe deployment, sensors that detect bumps in the road and automatically adjust suspension systems, and fluid level detectors for radiator, oil and gas levels. Potential medical uses include the development of a mattress-installed breathing monitor to guard against Sudden Infant Death Syndrome, and heart monitors that act like an electrocardiogram except that they measure the heart's actual contractions instead of its electrical impulses. Some potential home safety uses include intrusion detection systems that are less susceptible to false alarms, and space heaters that turn themselves off when a child comes nearby. Other interesting UWB applications include liquid level sensors for everything from water conserving toilets to oil refinery tanks and the use of UWB technology to allow auto focus cameras to calculate distances more accurately.

\section{Communications Applications}

12. Several parties noted that UWB devices can be used for a variety of communications applications involving the transmission of very high data rates over short distances without suffering the effects of multipath interference. Such devices could be used to wirelessly distribute services such as phone, cable, and computer networking throughout a building or home. UWB communications devices could also be utilized by police, fire, and rescue personnel to provide covert secure communications devices. Some parties believe that UWB technology would be useful for outdoor wide area communication systems.

\section{General Characteristics}

13. The comments suggest that UWB devices will have a variety of technical characteristics depending upon the intended application. U.S. Radar Inc., Geophysical Survey Systems, Inc. (GSSI), and the U.S. Geologic Survey indicate that GPRs operate with center frequencies of up to $3 \mathrm{GHz}$, and with bandwidths of up to 2 to 3 times the center frequency. Lawrence Livermore National Laboratories (LLNL) expects that UWB devices will operate with a center frequency anywhere between $20 \mathrm{MHz}$ and $60 \mathrm{GHz}$, with bandwidths ranging from $150 \mathrm{MHz}$ to $30 \mathrm{GHz}$. Multi Spectral Solutions, Inc. (MSSI) indicates that it has developed systems for the U.S. Government operating in the bands $3050 \mathrm{MHz}, 225400 \mathrm{MHz}, 1.31 .7 \mathrm{GHz}, 2.2$ 2.7 GHz, 5.4 5.9 GHz and 9.0 $11.0 \mathrm{GHz}$ using bandwidths from $20 \mathrm{MHz}$ to $2 \mathrm{GHz}$. Time Domain provides a table of potential UWB applications and the frequency ranges in which they are likely to operate. In this table, Time Domain suggests that GPRs and long range military communications will tend to operate at frequencies below $1 \mathrm{GHz}$; law enforcement and emergency motion and imaging devices, high performance microphones, security fences, and other devices will operate in the $12 \mathrm{GHz}$ region; and devices such as road and runway inspection radars, law enforcement and emergency service mobile imagers, buried victim rescue, RF Asset ID and tracking devices, collision avoidance sensors, etc. will operate in the $28 \mathrm{GHz}$ region and above. Time Domain states that it has built a number of UWB radars and communications systems operating below $2 \mathrm{GHz}$ with bandwidths of up to $800 \mathrm{MHz}$.

14. GSSI indicates that GPRs typically have no more than $10 \mathrm{~mW}$ average power and $10 \mathrm{~W}$ peak power, but it has designed GPRs for the U.S. Government that use up to $200 \mathrm{~mW}$ average power and $1 \mathrm{~kW}$ peak power. ANRO Engineering, Inc., notes that it has designed intrusion sensors for protecting defined perimeters on water and land with average powers of up to $1 \mathrm{~mW}$ and peak powers of up to $1 \mathrm{~kW}$. MSSI also indicates that it has developed a variety of devices for the U.S. Government and the military with average powers between $2 \mathrm{~mW}$ and $100 \mathrm{~mW}$ and peak powers ranging between $0.2 \mathrm{~W}$ and $16 \mathrm{~W}$. MSSI anticipates that commercial UWB applications can be met with the same power levels given for spread spectrum and UNII devices of $1 \mathrm{~W}$ transmitter output power with a $6 \mathrm{dBi}$ antenna. 
15. The NOI also requested comment concerning the expected or desired operating distances for unlicensed UWB devices. GSSI expects GPRs to operate at depths from one meter up to tens of meters. Some parties suggest that most UWB devices will typically have operating distances from $1 \mathrm{~cm}$ to 30 meters. LLNL expects low power devices to have operating distances of $5 \mathrm{~cm}$, and up to 1000 meters for high power, long range devices.

16. We observe that UWB technology may have a variety of technical characteristics, depending upon the intended application. We have considered the technical information provided in the comments as the basis for developing proposed rule amendments and alternatives, as discussed further below.

\section{Regulatory Treatment}

17. In the NOI, the Commission suggested that most UWB devices should be regulated on an unlicensed basis under Part 15 of the rules. However, the NOI requested comment on whether there are certain types of UWB devices or applications that should be regulated on a licensed basis under some other FCC rule part. The Ultra-Wideband Working Group (UWBWG), Zircon Corp., Clifford Harter, TEM Innovations, Time Domain Corp., Rosemount Measurements, and ANRO Engineering favor utilizing an unlicensed regulatory approach under Part 15 of the rules. The Wireless Information Networks Forum (WINForum) believes that some form of licensing is appropriate for UWB devices that deliberately emit energy in restricted frequency bands. Oak Ridge National Laboratory, TEM Innovations, LLNL, and Arthur D. Little, Inc. believe that some form of licensing should be provided for low volume, higher power UWB device operations. Zircon generally supports unlicensed operation for UWB devices that meet the emissions limits for Class $B$ digital devices. Zircon argues that the Commission should also permit UWB devices that meet the emissions limits for Class A digital devices to operate on an unlicensed basis under Part 15, but these devices should be coordinated with NTIA and registered in a data base listing the users and their locations. Zircon asserts that individual licensing may be necessary for devices operating above the Class A limits. GSSI suggests that UWB devices that radiate less that $10 \mathrm{~mW}$ average power and $1 \mathrm{~kW}$ peak power should be unlicensed.

18. Upon reviewing all the comments, we observe that most of the near-term applications for UWB technology involve relatively low powers and short operating ranges. Further, we note that most UWB devices are intended to be mass marketed to businesses and consumers and that individual licensing of each device would be impractical. These characteristics are largely consistent with devices that operate on an unlicensed basis under Part 15 of the rules. Accordingly, we tentatively conclude that it is appropriate to regulate under Part 15 of the rules low power UWB devices intended to be mass marketed to businesses and consumers.

19. We request comment on our proposal to accommodate very low power UWB devices within Part 15 of the FCC rules. We recognize that UWB technology may be developed for higher power applications such as wide-area mobile radio services. However, we find that such applications raise many new and novel questions, such as consistency with the international and domestic table of frequency allocations, and how such services might be licensed to share spectrum across broad frequency ranges used by multiple existing services and licensees. We observe that there is insufficient information in the record to address such issues. Accordingly, we are not making any proposals at this time to allow high power UWB devices to operate under Part 15 or on a licensed basis.

\section{UWB Definition}

20. In the NOI the Commission recognized that rules may need to be developed specifically for UWB devices and invited comment as to an appropriate definition for UWB. Several of the commenters suggested that we adopt the UWB definition established by the OSD/DARPA UWB radar review panel. That definition states that UWB devices must have a -20 dB fractional bandwidth of at least 0.25. In order for the fractional bandwidth to equal or exceed 0.25 , the $20 \mathrm{~dB}$ bandwidth must be at least $25 \%$ of the center frequency. Under this formula, the minimum $20 \mathrm{~dB}$ bandwidth is 250 megahertz if the center frequency is $1 \mathrm{GHz}, 1.25$ gigahertz if the center frequency is $5 \mathrm{GHz}$, and 2.5 gigahertz if the center frequency is $10 \mathrm{GHz}$. Alternatively, M/A-Com suggests that a distinction between devices that operate above and below $10 \mathrm{GHz}$ is needed because at higher frequencies the benefits of UWB may be achieved with lower fractional bandwidths. M/A-Com believes that UWB should be defined as a fractional bandwidth of at least 25 percent for devices operating below $10 \mathrm{GHz}$ and a bandwidth of at least $2.5 \mathrm{GHz}$ for devices operating above $10 \mathrm{GHz}$, based upon $-20 \mathrm{~dB}$. Milltronics offers that we should allow UWB to comprise a 
pulse transmission using a burst of controlled or stabilized carrier frequency where burst length is less than $3 \mathrm{nS}$ and the pulse repetition frequency ("PRF") is less than $5 \mathrm{MHz}$. Interval Research Corp. (Interval) believes that UWB devices should be defined as any device having a fractional bandwidth greater than .25. MSSI suggests that, instead of defining the term UWB, we should define and apply the term "bandlimited short impulse," or "bandlimited impulse," because UWB devices are better categorized by their duty cycle, or excess bandwidth ratio, rather than by their fractional bandwidth. Rosemount Measurement believes that any device that has a spectrum usage greater than $1.5 \mathrm{GHz}$ should be considered UWB. Other commenters made similar suggestions, but asked that we take antenna characteristics into account when determining emission bandwidth. SAAB Marine Electronics asserts that a device using a fairly smooth frequency spectrum with a bandwidth greater than 5 percent of the center frequency should be considered UWB.

21. We preliminarily believe that the definition established by the OSD/DARPA UWB radar review panel is appropriate with some modifications. Specifically, we are proposing to define UWB devices as any device where the fractional bandwidth is greater than 0.25 or occupies $1.5 \mathrm{GHz}$ or more of spectrum. This modified definition will avoid situations where devices operating at several gigahertz and above might unnecessarily use wide bandwidths simply to qualify as an UWB device. We are also proposing to base the definition of an UWB device on the $10 \mathrm{~dB}$ bandwidth rather than the $20 \mathrm{~dB}$ bandwidth. We propose this modification because UWB devices will operate so close to the noise floor that in many cases it will not be possible to measure the $20 \mathrm{~dB}$ bandwidth. For the purpose of this definition, we will define the center frequency of the transmission as the average of the upper and lower $10 \mathrm{~dB}$ points, i.e., ( $f H+f L) / 2$, as noted earlier. Finally, we are proposing that the bandwidth be determined using the antenna that is designed to be used with the UWB device. We invite comment on this proposed definition and whether the fractional bandwidth should be changed to account for the narrower bandwidth that would be measured using the $10 \mathrm{~dB}$ emission points instead of the $20 \mathrm{~dB}$ points. We request comment on whether we should use some other method to determine the emission bandwidth, such as a calculated bandwidth based on pulse width. We also request comment on whether we should define UWB devices as limited to devices that solely use pulsed emissions where the bandwidth is directly related to the narrow pulse width. We recognize that other types of modulation, such as linear sweep FM, could be employed to produce UWB equipment. However, we do not believe that we have sufficient information to propose limits and measurement procedures for such systems. Until more experience is gained, we believe that our initial rule making proposals should reflect a conservative approach. In addition, we request comment on whether extremely high speed data systems that comply with the UWB bandwidth requirements only because of the high data rate employed, as opposed to meeting the definition solely from the narrow pulse width, should be permitted. Finally, we request comment on any alternative definitions that may be appropriate.

\section{Frequency Bands of Operation}

22. In the NOI, the Commission noted that Part 15 designates certain sensitive and safety-related frequency bands as restricted bands. Only spurious emissions not exceeding the general emission limits are permitted within these restricted bands or, with few exceptions, within the frequency bands allocated for TV broadcasting. Comments were requested on whether the Commission should eliminate the requirement that only spurious emissions be permitted within the restricted bands and the TV broadcast bands. Comments were also requested on whether UWB operation should be permitted in certain restricted bands and the impact that retaining certain restricted bands may have on the viability of UWB technology.

23. Most of the commenting parties agree that the majority of UWB systems cannot avoid transmitting within the restricted bands. In some cases, particularly with GPRs, it is necessary that the equipment operate in the restricted bands and TV broadcast bands below $2 \mathrm{GHz}$ in order to obtain sufficient ground penetration to detect or image objects. A number of parties raised concerns that UWB devices could cause harmful interference to existing radio operations in the restricted frequency bands, TV broadcast bands, amateur radio frequency bands and others. Several parties raised particular concerns about potential interference to GPS operating in the frequency band $15591610 \mathrm{MHz}$. The U.S. GPS Industry Council argues that UWB operation should be limited to spectrum well above $1610 \mathrm{MHz}$, preferably above 3 $\mathrm{GHz}$, to protect GPS operations from harmful interference. With regard to retaining certain restricted bands, several comments opposed the use of filters to avoid operation within those bands. As stated by Time Domain, the addition of filters to notch out portions of the transmitted spectrum would result in higher cost and would disperse the waveform over time due to complex ringing modes of the filter tuned circuits. Time Domain adds that the requirement to use notch filters would render UWB infeasible by decreasing the signal 
to noise ratio, reducing available processing gain, decreasing ranging and positioning capability and removing multipath immunity and jamming resistance. MSSI argues that UWB operations should be confined to frequencies above $2 \mathrm{GHz}$. Interval suggests that we initially allow UWB operations only in the frequency band 2.9-4.99 GHz.

24. We have considered a number of factors in addressing what frequency bands should be made available for UWB devices. First, we believe that it is vitally important that critical safety systems operating in the restricted frequency bands, including GPS operations, are protected against interference. Second, we believe that there are a broad variety of potential applications for UWB technology, each of which has unique spectrum attributes and requirements. Third, we note that the various regions of the spectrum have different propagation characteristics. As Arthur D. Little, Inc. points out, for example, an UWB signal operating at the general emission limits in 47 C.F.R. 15.209 would fall below a victim receiver's thermal noise at a distance of 40 meters at $500 \mathrm{MHz}$, and at a distance of 10 meters at $5 \mathrm{GHz}$.

25. We have developed a number of alternative proposals based on these considerations. We observe that GPRs must operate at frequencies in the region below $2 \mathrm{GHz}$ in order to obtain the penetration depth and resolution necessary to detect and obtain the images of buried objects. GPRs can neither avoid nor notch out the restricted frequency bands. We believe the risk of interference from GPRs is negligible because the overwhelming majority of their energy is directed into the ground where most of the energy is absorbed. Emissions in other directions can be easily shielded without affecting the operating characteristics of the GPR. In addition, GPRs are expected to have a low proliferation and usually operate at infrequent intervals. Thus, the interference potential of these devices should be low. We also note that, according to the comments, these devices have been used in limited numbers for quite some time for both government and non-government applications without any known instances of harmful interference. Accordingly, we propose to allow GPRs to operate in any part of the spectrum, subject to the emissions limits discussed below. We propose to define a GPR as an UWB device that is designed to operate only when in contact with, or in close proximity (i.e., 1 meter) to, the ground for the purpose of detecting or obtaining the images of buried objects. We also propose to require GPRs to include a switch or other mechanism to ensure that operation occurs only when it is activated by an operator and the unit is aimed directly down at the ground. We invite comment on these proposals.

26. The situation is less clear with regard to UWB devices that would be used to detect or obtain the images of objects inside or behind walls or other surfaces. In particular, it is unclear whether the same arguments that apply to GPRs concerning penetration depth and resolution similarly apply to other imaging devices. In contrast to GPRs, where signals are aimed at the ground, through-wall imaging devices could aim their energy in any direction. While the wall could attenuate these signals, the amount of attenuation can vary widely depending on the composition of the wall. We note that such systems would be expected to have a low proliferation and would be operated infrequently. One option would be to treat all imaging devices the same way as GPRs. Alternatively, we could restrict the operation of such devices below a certain frequency. We invite comment on these alternatives and any other approaches that may be appropriate. Comments also are requested on what provisions are needed to ensure that these systems operate only when they are in contact with a wall. In addition, comments should address whether the operation of through-wall imaging systems should be limited to parties eligible for licensing under the Public Safety Pool of frequencies in Part 90 of our rules, as required under the earlier waiver to Time Domain. Comments also are requested on whether through-wall imaging systems should be required to incorporate automatic power control features that would reduce power levels to the minimum necessary to function based on the composition of the surface and its absorption of RF energy.

\section{Response to item 26: Use of directional antennas could be mandated to resolve the interference issues in this application.}

27. We observe that most other applications for UWB technology could operate in a variety of regions of the spectrum. To realize the full benefits of this technology, we believe that we should establish as few restrictions as possible on the operating frequencies, except as necessary to protect existing services against interference. We believe that UWB devices can generally operate in the region of the spectrum 
above approximately $2 \mathrm{GHz}$ without causing harmful interference to other radio services. The UWB signals will quickly fall off below the background noise because of the high propagation losses at $2 \mathrm{GHz}$ and above. Further, most radio services operating above $2 \mathrm{GHz}$ use directional antennas that generally discriminate against reception of undesired signals. Accordingly, we are not proposing any restrictions on UWB devices operating at frequencies above approximately $2 \mathrm{GHz}$. We invite comment on this proposal.

27. Recommend allocating a high upper frequency (infinity is good) to provide minimum interference to existing narrowband systems.

28. We have a number of concerns about generally permitting the operation of UWB devices in the region of the spectrum below approximately $2 \mathrm{GHz}$. This is perhaps the most heavily occupied region of the spectrum and is used for public safety, aeronautical and maritime navigation and communications, AM, FM and TV broadcasting, private and commercial mobile communications, medical telemetry, amateur communications, and GPS operations. We note that 41 of the 64 restricted frequency bands are at or below $2 \mathrm{GHz}$, not counting the TV broadcast bands. We are particularly concerned about the impact of any potential interference to the GPS band at $15591610 \mathrm{MHz}$. We also would be concerned about interference to any additional frequencies allocated to GPS, e.g., the planned L5 frequency in the 960-1215 $\mathrm{MHz}$ band. As pointed out by many of the comments, GPS will be increasingly relied upon for air navigation and safety, and is a cornerstone for improving the efficiency of the air traffic system. We note also that GPS may be used by commercial mobile radio E-911 services to enable police and fire departments to quickly locate individuals in times of emergency. Moreover, use of GPS is expanding for use by businesses and consumers for all sorts of applications, such as for navigation by automobiles, boats and other vehicles, surveying, hiking, and geologic measurements. Therefore, any harmful interference to GPS could have a serious detrimental impact on public safety, businesses and consumers. We note, in addition, that propagation losses are not as great below $2 \mathrm{GHz}$, and services in this region of the spectrum tend to employ omni-directional antennas that do not discriminate against undesired signals. These factors tend to increase the risks of interference below $2 \mathrm{GHz}$.

29. In light of these factors, we have significant concerns about the operation of UWB devices, except for GPRs and possibly through-wall imaging devices, in the region of the spectrum below approximately $2 \mathrm{GHz}$. As explained earlier, we believe that it is vitally important to ensure that critical safety systems, including GPS operations, are protected from harmful interference. We invite comments on UWB operations, potential restrictions on operation for UWB below $2 \mathrm{GHz}$, and the impacts such restrictions would have on any potential applications for UWB technology. We also invite comment as to the precise frequency below which operations of UWB devices may need to be restricted. For example, should we restrict operations below the GPS band at $1610 \mathrm{MHz}$, or below the restricted band at $1718.8-1722.2 \mathrm{MHz}$, or below the Personal Communication Service band at $1850-1990 \mathrm{MHz}$, or some other frequency? What should be the limit of any restrictions?

30. We also wish to consider a number of alternative approaches to expressly prohibiting operations in the frequency bands below $2 \mathrm{GHz}$. For example, we note that certain UWB applications may be feasible using extremely low signal levels. We invite comment as to whether and at what levels, if any, we should permit operation in the restricted bands below $2 \mathrm{GHz}$ for devices that can operate using extremely low signal levels. While we recognize that UWB technology generally cannot completely notch out frequency bands that are a subset of their operating frequencies, we invite comment as to the viability of establishing a general emission limit for UWB devices below $2 \mathrm{GHz}$, and whether a very stringent limit, or notch, should be applied to the GPS band. Comments are invited on these alternatives and any others that may be appropriate for regulating the frequencies of operation of UWB devices. Even though we are considering restricting the operation of UWB devices from use below approximately $2 \mathrm{GHz}$, we will consider allowing access to this spectrum provided that test results and detailed technical analyses are submitted demonstrating that there is no risk of harmful interference to GPS, to other services operating in restricted frequency bands, or to TV broadcasting.

\section{Further Testing and Analyses}

31. As noted above, we understand that various parties are planning experimental programs to study the interference potential of UWB devices. NTIA is planning a study at its Institute for Telecommunications 
Sciences in Colorado. The Department of Transportation has already contracted with Stanford University for tests to examine potential interference to GPS receivers. We also understand that certain manufacturers of UWB devices and other interested parties are planning tests. We welcome these testing programs and believe that the information they yield will be important for developing emission limits for UWB devices that will protect other radio services against interference. Commission staff will monitor the progress of these tests. We would like to encourage all of the interested parties to work together cooperatively so that this work can be completed in a timely and efficient manner. We encourage parties to submit the test results into the record in this proceeding by October 30,2000. At the appropriate time, we will issue a public notice to provide an opportunity to provide comments and replies on the test results and analyses.

32. We recognize that the establishment of emissions limits requires a firm understanding of the characteristics of UWB signals, their impact on victim receivers, and the minimum separation distance between UWB devices and victim receivers. Almost any transmitter will cause interference if it is too close to a receiver. For example, in the case of personal computer emissions our goal has been to provide TV broadcast receivers with a $45 \mathrm{~dB}$ signal-to-interference ratio within the grade $A$ contour where the personal computer is separated from the TV receiver by 10 meters with an $8 \mathrm{~dB}$ separating wall. Thus, as parties perform measurements and analyses of UWB devices we ask that they consider and provide information on receiver susceptibility to UWB signals along with the spatial geometries assumed for the susceptibility studies.

33. There are several possible interference mechanisms for receivers. We request that comments discussing interference risk to a particular service identify the specific interference mechanisms they are concerned about and provide the following information, if possible: 1) typical desired signal strengths at receivers in that service; 2) receiver inherent noise level or noise figure; 3) typical antenna patterns for the system and frequency response of the antenna for out-of-band signals indicating expected differential antenna gain for UWB signal and desired signal if applicable; 4) typical front end bandwidths before the first mixer in receivers; 5) typical dynamic range limits of receiver mixers preferably third order intercept points; 6) typical IF bandwidths; 7) required signal-to-interference ratios for reliable performance of the system assuming interference is white gaussian noise and with others types of interference; 8) required interference to noise ratio; and 9) minimum distance to an interference source that is not under the control of the user. While it is helpful to know the signal level of a particular UWB emission that causes interference to a class of receivers, we would like to extrapolate measurements to a variety of UWB signals so that the designers of UWB devices will have flexibility in their waveform design. For example, some of the parties filing comments on the NOI felt that emission limits should be based on the unintentional emission limits for digital devices contained in Section 15.109 of our Rules, with a possible adjustment of the quantitative limit. Above $1 \mathrm{GHz}$, this rule limits average field strength emissions to $150 \mathrm{uV} / \mathrm{m}$ at a distance of 10 meters measured over a bandwidth of $1 \mathrm{MHz}$. We request experiments and comments of whether this framework is an appropriate model for interference potential of UWB signals to other systems. For example, what types of systems are effectively modeled by such a protection criterion? What types of systems need a different type of protection criterion?

\section{Emission Limits}

34. In order to control harmful interference from UWB devices, it is important that we establish appropriate emission limits. In the NOI, the Commission noted that the current Part 15 rules are based on the equivalent of a power spectral density, i.e., a field strength limit is specified along with a measurement bandwidth. These emission bandwidths were chosen to protect various classes of receivers from interference. Further, the emission limits were established based on the potential interference from a single Part 15 device and do not take into account cumulative effects that could occur if a number of devices are located closely together. Comments were sought on the following questions: 1) Are the existing general emission limits sufficient to protect other users, especially radio operations within the restricted bands, from harmful interference or should different limits be applied to UWB systems; 2) Should standards be based on spectral power density and should those standards be designed to ensure that the UWB emissions appear to be background noise; 3) What is the potential for interference due to the cumulative impact of emissions from multiple transmitters; 4) Should a limit on the total peak level apply to UWB devices; 5) Can emissions below or above a certain frequency range be further filtered to reduce interference potential without affecting UWB performance; 6 ) Are the existing limits on the amount of energy permitted to be conducted back onto the $A C$ power lines appropriate for UWB devices; 7) What operational restrictions, if any, should be required to protect existing 
spectrum users; and 8) Is the use of UWB modulation techniques necessary for certain types of communication systems and, if so, for what purposes?

35. As noted above, several comments filed in response to the NOI suggested that the Commission should adopt the same emissions limits for UWB devices as already exist for unintentional radiators, such as digital devices. Others argue that we should apply the general emissions limits for intentional radiators, but disregard pulse desensitization when performing measurements, effectively allowing higher peak levels than permitted under the current rules. The radiated emissions limits below $1 \mathrm{GHz}$ are based on measurements with a quasi-peak detector, which effectively provides an average reading with some weighting for peak signal levels. The radiated emissions limits for both intentional and unintentional radiators above $1 \mathrm{GHz}$ are based on measurements using an average detector. However, intentional radiators are also subject to a requirement that the total peak levels of emissions above $1 \mathrm{GHz}$ must be no greater than $20 \mathrm{~dB}$ above the average limits. Based on the comments on the NOI, it appears that the peak levels for UWB devices could be up to $60 \mathrm{~dB}$ higher than the average levels. This difference is significant because these higher peak levels could lead to an increased risk of interference to certain receivers. For example, if the pulse repetition frequency of the UWB signal is much greater than the bandwidth of a receiver, the emission may appear to be random noise, the effect of which is proportional to the average power in the UWB signal within the receiver's bandwidth. However, if the PRF is less than the receiver's bandwidth, the UWB signal may appear to the receiver as impulsive noise and the effect would be proportional to the peak power of the UWB signal. We also note that UWB devices spread their emissions over a wide bandwidth as compared to most current intentional and unintentional radiators. As a result, receivers that use wide bandwidths are likely to receive more total energy from UWB devices than from most other existing Part 15 devices. Accordingly, we believe that special consideration is needed to develop emissions limits for UWB devices.

36. We tentatively conclude that it is necessary to regulate both the peak and average emission levels above $1 \mathrm{GHz}$ and the quasi-peak emission levels below $1 \mathrm{GHz}$ from UWB transmitters, just as we regulate these emission levels for most other types of Part 15 transmission systems. The impact of UWB signals on a receiver appears to depend on the randomness of the UWB signal and the relationship between the pulse repetition frequency (PRF) of the UWB signal and the bandwidth of the receiver. If the UWB pulses are spaced evenly in time and each pulse is exactly the same (as in many radar systems), then classic communications theory shows that the spectrum consists of narrow spectral lines spaced at the PRF. The impact of these signals on a receiver can be modeled by treating each spectral line as a narrowband conventional signal. This gives rise to one possible way to increase protection to GPS receivers from UWB GPR and through-wall imaging devices. Since repetitive identical pulses are often applicable to GPRs and through-wall imaging devices, it may be possible for designers to select system parameters to avoid GPS signal bands and thus avoid co-channel interference. It also may be possible to space the UWB signal's spectral lines in places within the GPS band where GPS receivers are less sensitive to interference. We request comment on whether this technique is applicable to all types of GPRs and through-wall imaging devices and the cost implication of using a stable frequency reference to ensure the PRF creates a signal avoiding the GPS bands.

37. For UWB communications systems, the emitted spectrum depends on the information being sent. If the information is unchanging, such as a steady string of zeroes in the case of digital information, the transmitted signal may become a set of spectral lines that has different interference potential than the noiselike spectrum that would be produced under normal modulation. Depending on exactly where these spectral lines are, the interference potential may increase. This could be avoided by using scrambler technology, often used in digital wireline and optical communications systems, which prevents long strings of unchanging bits. We seek comment on whether we should require such scrambler technology for UWB communications systems or, alternatively, a performance requirement that would show that the transmitted spectrum remains noise like in the case of unchanging input data.

38. Average and quasi-peak emission levels. Several commenting parties indicated that the general emission limits contained in Part 15 appear to be sufficient to control potential interference problems, noting that there has been no increase in interference complaints regarding Part 15 devices despite the geometric increase in the number of these devices. Some of the commenters stated that the interference would be no greater than that caused by the many unintentional radiators currently operating under Part 15. Interval and the UWBWG, among others, requested that the same levels applied to digital devices be applied to UWB products, including the higher limits currently applied to Class A digital devices used in non-residential environments. On the other hand, some of the comments requested that UWB be permitted to operate at 
power levels that would exceed the general emission limits. For example, ANRO Engineering, GSSI and Krohne request that an average power of $10 \mathrm{~mW}$ be permitted. MA/COM requests levels as high as 250 $\mathrm{mV} / \mathrm{m}$ at 3 meters. Most of the commenting parties agreed that output limits should be based on spectral power density to reduce potential interference. However, other commenting parties expressed concern that operation at the general emission levels could result in harmful interference to GPS, Federal Aviation Administration systems, and weather radars at airports. The ARRL also expressed concern about interference to amateur operations should emissions be permitted at the general limits, requesting that additional experience with equipment operating under waivers is needed before rules are developed.

39. The Part 15 general emission limits have a long and successful history of controlling interference to other radio operations. However, we also recognize that the general emission limits were never designed to protect against all possibilities of harmful interference. Rather, these limits were designed to protect neighbors from causing interference to each other. These limits were designed as a reasonable compromise to protect the authorized radio services from receiving harmful interference without requiring an analysis of the individual needs of every type of receiver design used in every radio service. We remain committed to protecting the authorized radio services from receiving harmful interference from Part 15 devices. We are especially concerned about protecting radio services used for safety-of-life applications, such as GPS, from such interference. Accordingly, we believe that the general emission limits contained in 47 C.F.R. Section 15.209 appear appropriate for UWB operations. These emission limits are already based on a spectral power density, measuring signal level per unit bandwidth. As discussed above, we also are proposing that additional protection be provided below approximately $2 \mathrm{GHz}$ for emissions from UWB devices. For emissions from UWB devices other than GPRs and, possibly, through-wall imaging systems, we tentatively propose that emissions that appear below approximately $2 \mathrm{GHz}$ be attenuated by at least 12 $d B$ below the general emission limits. We believe that this attenuation below the general emission levels will provide additional protection to the congested spectrum below $2 \mathrm{GHz}$ without affecting the viability of UWB operations. Comments are requested on whether such an attenuation level is necessary, or whether additional attenuation below $2 \mathrm{GHz}$ is possible or necessary. We also seek comment on whether the proposed reduction in the emission levels should apply to all emissions below $2 \mathrm{GHz}$ or only to emissions below $2 \mathrm{GHz}$ that fall within the restricted bands shown in 47 C.F.R. 15.205. Comments also are requested on whether UWB devices other than GPRs, and possibly through-wall imaging systems, should be permitted to operate below $2 \mathrm{GHz}$ provided they comply with these reduced emission levels.

Commenting parties should address any additional changes to the technical standards or to the operational parameters of UWB transmitters that could be employed to facilitate the operation of these products below 2 $\mathrm{GHz}$.

40. We do not agree with the assessment of some of the comments that characterize the emissions from UWB systems as having the same potential for causing harmful interference as emissions from unintentional radiators. Unintentional radiators are permitted to radiate anywhere within the spectrum at the general emission limits. In most cases, unintentional radiators, as well as most conventional Part 15 transmitters, generate emissions on only a few narrow frequencies that approach the general limits; the other emissions are well below these limits. However, the emissions from UWB transmission systems are considerably different from those of unintentional radiators and conventional Part 15 transmitters. The high peak to average ratio of emissions, the extremely narrow pulse widths, and the pulse repetition frequencies employed by UWB devices serve to differentiate UWB products from other Part 15 devices. In particular, the emissions from UWB transmitters could be near the maximum permitted levels over several gigahertz of spectrum. Because UWB devices produce a wider range of emissions approaching the maximum emission levels, we also disagree with the comments that we should apply the Class A digital device emission limits to UWB products used in non-residential environments. Further, the difficulty in controlling the location of UWB devices, as demonstrated with our past experience with computers, and the potential that UWB products could have higher incidences of unshielded outdoor applications than digital devices could result in UWB devices causing a greater amount of harmful interference to other radio operations than digital devices. In addition, we do not agree with the comments that emission levels should be based on measurements taken outside of the building in which the equipment is located. Building attenuation varies widely based on the location of the equipment within the building and the composition of the building. It would be necessary to test UWB devices in every installation to ensure compliance with the standards; this presents an unreasonable test condition for the Commission, the manufacturers and the product users. Further, many of the proposed UWB products would be mobile devices, and it hardly seems likely that these products would be operated only within buildings. We believe that the emission limits being proposed in this Notice are a reasonable starting point for establishing standards. As equipment continues to be developed 
and additional experience is gained with this equipment, future changes to the standards may be considered.

41. Peak emission limits. Those parties wishing to manufacture UWB devices expressed concern that establishing too low of a peak limit would preclude UWB devices that inherently have a high peak to average ratio. As indicated by WINForum, peak output does not directly impact interference seen by a narrowband receiver; it is the power spectral density of the pulse and the pulse repetition frequency that are important for controlling potential interference. On the other hand, the comments also expressed concern that the peak emission levels produced by UWB devices could cause harmful interference.

42. We believe that a limit on peak emissions is necessary to reduce the potential for UWB emitters to cause harmful interference to radio operations above $1 \mathrm{GHz}$. However, before we can propose a limit for peak emissions we first must clarify what is meant by peak for UWB applications. In the past, we have used a variety of peak definitions for different types of Part 15 devices in order to match the interference potential of the system being regulated to the necessary parameters. For example, for unlicensed spread spectrum systems we regulate the "maximum peak output power" while for unlicensed National Information Infrastructure ("U-NII") devices we use a definition based on average peak power over the transmitting interval. For most Part 15 devices, peak emission levels are field strength levels measured with a spectrum analyzer that is calibrated in terms of an RMS-equivalent voltage. Thus, the peak level measured by a spectrum analyzer results in an RMS value of the true peak. For the purposes of regulating UWB emissions, we propose two methods of measurement: 1) the peak level of the emission when measured over a bandwidth of $50 \mathrm{MHz}$ which we believe is comparable to the widest victim receiver that is likely to be encountered, and 2) the absolute peak output of the emission over its entire bandwidth. Comments are requested on the suitability of these two measurements with regard to the potential for interference from UWB transmitters to wideband receivers used in the licensed radio services.

43. In the case of the first definition of peak level, i.e., the peak signal strength measured over a $50 \mathrm{MHz}$ bandwidth, we propose to apply a $20 \mathrm{~dB}$ limit with respect to the maximum permitted average emission level. This limit is consistent with the limit currently contained in 47 C.F.R. 15.35(b). We further propose that the absolute peak limit for the emission over its entire bandwidth be variable based on the amount the $10 \mathrm{~dB}$ bandwidth of the UWB emission exceeds $50 \mathrm{MHz}$. We propose to use the following formula to calculate the amount that the absolute peak emission level over the entire bandwidth of the UWB emission would be permitted to exceed the Part 15 average emission limit: $[20+20 \log 10(-10 \mathrm{~dB}$ bandwidth of the UWB emission in Hertz/50 MHz)] dB. In addition, we propose that the absolute peak emission level not be permitted to exceed the average limit by more than $60 \mathrm{~dB}$. This $60 \mathrm{~dB}$ limit is comparable with the limit permitted under the waivers recently issued to Time Domain Corporation, U.S. Radar Inc. and Zircon Corporation. For example, an UWB emission with a $10 \mathrm{~dB}$ bandwidth of one gigahertz would be permitted an absolute peak emission level over the total bandwidth of the emission of $46 \mathrm{~dB}$ above the maximum permitted Part 15 average emission level. Similarly, an UWB emission with a $10 \mathrm{~dB}$ bandwidth of 5 gigahertz or greater would be permitted an absolute peak emission level over the total bandwidth of $60 \mathrm{~dB}$ above the maximum permitted average emission level.

First, we assume the dB's referred to in the first sentence and the formula for computing power in paragraph 43 are actually $\mathrm{dBm}$. 
The power limits proposed were obviously very well reasoned and considered. Some minor changes that might be considered are outlined below

Recommend setting a minimum frequency spread on emissions. One possible wording might be: Given a total average power $\mathrm{P}$ in the bandwith $\mathrm{Bw}$ ( 2 to 5 ? $\mathrm{GHz}$ frequency band), no more than ten times the fractional power may lie within any fractional bandwith $(10 * \% \mathrm{P} / \% \mathrm{Bw})$. For example, if $50 \%$ of a transmitters power lies within $5 \%$ of the allocated bandwidth, the transmitter would fail for concentrating too much power in too little bandwidth.

The reason for spreading the UWB energy evenly becomes apparent upon studying figure xx. Optimal NB-WB isolation occurs when narrow-band systems are kept narrow and wideband systems are kept wide.

There are two types of interference mechanisms to be considered prior to rule changes, in-band and out-of-band. In-band interference can be simply estimated by calculating the power density of the offending transmitter in a potential narrowband receiver bandwidth.

If an UWB transmitter is directly connected to the antenna terminals of a narrowband receiver, the formula for calculating the interference level is:

$$
\text { Eq. } 1 \quad \mathrm{P}_{\text {Interference }}=\mathrm{Ptav} \bullet \mathrm{Dc} \cdot \mathrm{Bw}_{(\mathrm{NB})} / \mathrm{Bw}_{(\mathrm{UWB})}[\mathrm{mW}]
$$

Where $\mathrm{P}_{\text {Interference }}$ is the power at the narrowband receiver antenna terminals, $\mathrm{Pt}$ is the offending UWB average transmitter power, Dc is the offending UWB transmitter duty cycle and Bw are the bandwidths.

Example, if a $0.1 \%$ duty cycle UWB transmitter spreads its power over $3 \mathrm{GHz}$, and a narrowband receiver bandwidth is $10 \mathrm{kHz}$, then only $-85 \mathrm{~dB}$ of the offending signal is captured by the narrowband receiver. Add a few inches of distance between the two systems and isolation can be more than $120 \mathrm{~dB}$.

To interfere out of band requires such high power level that it should not be considered further. LLNL and DoD studies have shown that out of band interference (and with more power, damage) only occur at very high power levels. Impulsive average powers must



One interesting thing to note about Equation 1 is that it depends (linearly) upon duty cycle. One of the great strengths of UWB is that the system need only use information bandwidth (time slots) as required. Should one have a sensor that only needs to report once per second, an UWB system might only need to send a few impulses per second. The duty cycle may be $0.00001 \%$ or less. Recommend that the FCC encourage low duty cycle use by all systems. The $60 \mathrm{~dB}$ (and equation rule for narrower bandwidth) rule does not encourage low-duty cycles below $1 \%$ (for the 200 ps pulses available today). Therefore, one might consider an absolute peak power limit be set in addition to the average power limit (e.g. $80 \mathrm{dBm}$ peak power maximum) or some other accommodation for low duty cycle systems. 
All will benefit from fewer pulses being in the air at any given time.

Recommend the maximum allowable average power radiated be based on the in-band interference. By rearranging equation 1, the UWB transmitted power can be calculated.

$$
\text { Eq. } 2 \operatorname{Ptav}=\mathrm{Dc} \bullet \mathrm{Bw}_{(\mathrm{NB})} /\left(\mathrm{Bw}_{(\mathrm{UWB})} \cdot \mathrm{P}_{\text {Interference }}\right)[\mathrm{mW}]
$$

By allowing the duty cycle to be $100 \%$, the average power and the peak power become equal $($ Ptav $=$ Ptpeak $=$ Pt $)$.

$$
\text { Eq. } 3 \mathrm{Pt}=\mathrm{Bw}_{(\mathrm{NB})} /\left(\mathrm{Bw}_{(\mathrm{UWB})} \cdot \mathrm{P}_{\text {Interference }}\right)[\mathrm{mW}]
$$

Power now only depends on the ratio of UWB and narrowband bandwidths and the allowable interference level. If the bandwidth ratio conformed to the previous example ( $3 \mathrm{GHz}$ gigaHertz UWB, and a narrowband receiver bandwidth of 10 kiloHertz ) and $500 \mu \mathrm{W}$ at 3 meters (isotropic radiators) were acceptable, then allowable UWB power would be roughly $80 \mathrm{~mW}(19 \mathrm{dBm})$. Should the designer wish to reduce his duty cycle to $1 \%$, he would be allowed $39 \mathrm{dBm}$ peak power (retaining $19 \mathrm{dBm}$ average power).

There was also some debate here as to whether the peak power limit dropped-off at low duty cycle (dashed in figure $\mathrm{xx}$ ) or remained constant. Perhaps some clarifying language could be included.



Figure: Recommended peak power limits encourage low duty cycle transmitters. 
44. We do not believe that allowing such a high absolute peak signal relative to the Part 15 average limit will significantly increase the potential for harmful interference to other radio operations due to the wide spreading of the transmitted energy that is being required. We request comment as to whether the higher absolute peak limit will cause increased interference problems, especially using the proposed measurement procedures described below and with the limitations on frequency bands of operation described above. Comments are requested on the proposed method of varying the absolute peak emission limit and whether other features, such as the excess bandwidth, i.e., the amount of the occupied bandwidth/effective data rate exceeds a specified level such as $10 \mathrm{~dB}$, should be employed in calculating a peak limit. Comments also are requested on whether wideband receivers used in the licensed services are sensitive to peak signal level in a unit bandwidth, such as the $50 \mathrm{MHz}$ reference above, or to the total peak emission produced by the USB device, and whether both peak limits are needed to reduce potential interference to the authorized radio services. If only one peak limit is needed, the comments should indicate which limit is appropriate. We intend to rely heavily on submitted test data in determining what peak emission standards should apply to UWB products.

45. AC power line conducted limits. The commenters were in agreement that the existing $A C$ power line conducted limits are not a burden and should be applied to UWB devices. However, several potential UWB manufacturers requested that a higher limit be permitted for UWB devices used in non-residential environments, equivalent to the limits applied to Class A digital devices. For the same reasons cited above for the radiated emission levels, we do not agree that higher conducted limits should be permitted in nonresidential environments. Besides the difficulty in controlling the location in which the product will be used, as demonstrated with our past experience with computers, UWB devices could have a higher incidence of outdoor applications with negligible shielding of emissions radiated from the $A C$ power lines. We believe that the existing limit in 47 CFR Section 15.207 for controlling the amount of energy permitted to be conducted onto the $A C$ power lines is a reasonable starting point for establishing standards until additional experience can be gained with this equipment. We seek comment on this conclusion.

46. Cumulative impact. There was considerable variation among the comments regarding the effect of cumulative emissions from multiple, co-located UWB devices. Many parties indicated that a proliferation of UWB devices would have a negligible impact on the background noise level. Other parties express concern that there would be a cumulative effect and that this could impact vulnerable GPS and FAA radar systems. In particular, we note that the Commission's Technology Advisory Council, Spectrum Management Focus Group, reviewed analysis papers from four UWB technology firms, Time Domain, Interval Research, XtremeSpectrum, and A. D. Little Corp., and concluded that there would be no significant rise in the RF noise floor. Rather, that noise floor would be set by the closest UWB transmitters.

47. Nevertheless, as discussed above we believe that further testing and analysis is desirable on this issue. The cumulative impact appears to be negligible at the power levels and with the modulation types being proposed, especially when compared to the interference potential from a single land mobile transmitter. This leads us to believe that only the closest transmitter placing an emission on the frequency of concern would be of importance, obviating the need for additional attenuation to compensate for cumulative effects. However, the cumulative impact of several UWB devices may be different depending on their individual emission and transmission characteristics. For example, how does the cumulative impact of those UWB transmitters that emit a line spectrum compare to those that have a high level of random pulse 
positioning or dithering and may appear as Gaussian noise? Further, what is the relationship between pulse repetition frequency and the cumulative impact of a number of UWB devices? We look forward to receiving comments and test data from various parties along with relevant input from the Commission's Technical Advisory Council.

\section{Measurement Procedures}

48. In the NOI, the Commission addressed several questions on the measurement procedures that should be applied to UWB devices. The NOI noted that the current measurement procedures specify the frequency range over which measurements are to be made, as well as the measurement detector functions and bandwidths to be employed. It also noted that with conventional narrowband Part 15 transmitters the peak level provides an indication of the interference potential of the device by measuring the total amount of energy that may appear in the passband of a receiver. Comments were requested on the following questions: 1) Does the peak output level continue to be indicative of the interference potential of an UWB system; 2) Is a pulse desensitization factor appropriate for measuring UWB emissions or should another measurement procedure be employed; 3) Is the frequency of the fundamental emission readily discernible and are the current measurement ranges appropriate for UWB devices; 4) Are the current measurement detector functions and bandwidths appropriate for UWB devices or should these standards be modified; and 5) Are there any other changes to the measurement procedures that should be applied to UWB devices?

49. Under the existing rules, below $1 \mathrm{GHz}$ the emission levels are measured with a CISPR quasi- peak detector, and above $1 \mathrm{GHz}$ emissions are based on average and peak measurements. The comments offered several methods for measuring UWB emissions. Some parties requested the use of a simple procedure that employs a spectrum analyzer with resolution bandwidth (RBW) and video bandwidth (VBW) settings of $1 \mathrm{MHz}$. WINForum provided a detailed analysis of the different measurements that are needed to characterize the interference potential of UWB emissions. WINForum asserts that different measurement bandwidths are necessary depending on the pulse repetition frequency of the UWB transmitter and the bandwidth of the receiver being protected from interference. We recognize that WINForum raises a valid point. However, we believe it is important to develop measurement procedures that are reasonably simple and straightforward and can apply to a wide range of UWB devices. We hope that the additional testing of UWB devices that is expected to occur will provide valuable insight into the measurement procedures that should be applied. In the interim, the following paragraphs contain our tentative proposals.

50. Average and quasi-peak measurements. Below $1 \mathrm{GHz}$, we propose to require emissions to be measured using a quasi-peak detector, which effectively provides a weighted average. This approach is identical to the approach used under our current Part 15 rules for intentional and unintentional radiators. We invite comment on this proposal. Above $1 \mathrm{GHz}$, we propose to require average measurements to be made with a $1 \mathrm{MHz}$ resolution bandwidth ("RBW"), as we currently do for intentional and unintentional radiators. We also propose that spectrum analyzer video averaging with a video bandwidth ("VBW") of no greater than $10 \mathrm{kHz}$ or less than $10 \mathrm{~Hz}$ be used in conjunction with peak hold to determine the average level as a function of frequency. We believe that this is a simple and effective way to make the measurement but will consider alternative techniques that can be shown to give comparable or more accurate results.

51. Peak measurements. Most of the comments objected to applying a pulse desensitization correction factor (PDCF) to determine the total peak emission, stating that the PDCF has little meaning for an UWB emitter that may spread its energy over several gigahertz of spectrum. Magnetrol International states that peak levels can not be measured with a spectrum analyzer and suggested, along with ANRO Engineering, the use of a fast sampling oscilloscope or similar device to measure peak levels. As GSSI correctly points out, the PDCF was designed for use with pulse modulated sinusoidal carriers. We agree with the comments that the PDCF was not designed for the measurement of impulse systems due to the lack of a sufficient number of zero crossings in the waveform.

52. Based on these concerns, we now propose to measure the peak emission level of UWB signals directly in the time domain. The first proposed definition of peak output, i.e., peak level based on a measurement bandwidth of $50 \mathrm{MHz}$, is an untraditional one in the electromagnetic compatibility ("EMC") area and can not be measured with normal commercial EMC test equipment. However, microwave receivers designed for radar interception and analysis are available with such characteristics and have costs comparable to normal EMC test equipment. The IF output of a microwave receiver that uses a wide bandwidth, e.g., $50 \mathrm{MHz}$, can be analyzed using a conventional oscilloscope in order to measure the peak 
level of the waveform in the time domain. We seek comments on the feasibility of this testing technique as well as its utility as a model for the interference potential of peak UWB levels.

53. Under the second definition of peak emission level, i.e., the total peak output, we believe that this can be readily done with standard sampling oscilloscope techniques for UWB signals with evenly spaced identical elements, such as radar signals. For signals with modulation of their amplitude or spacing we believe that sampling oscilloscope technology can be used to measure the peak signal. We recognize that such measurement technology is more expensive than the equipment normally used for equipment authorization measurements, however such technology is typically used for the development of UWB systems. We also request comments on allowing peak measurements to be made with a spectrum analyzer using the PDCF, provided the applicant can show that the measurement as corrected by the PDCF is the true peak for the waveform being tested. We recognize that the peak level measured with a spectrum analyzer is the RMS peak and must be adjusted to obtain the true peak level. We seek comment on the types of UWB signals, if any, for which this latter measurement technique would be appropriate.

Recognizing that the width of the fundamental lobe would be affected by the measurement antenna bandpass characteristics, particularly with impulse systems, comments also are sought on whether the PDCF employed in the latter measurements should be calculated based on an effective pulse width, i.e., two divided by the bandwidth, in Hertz, of the emitted fundamental lobe.

54. For peak measurements of UWB signals, the antenna used in the measuring equipment could have an effect on the measured value. In particular, it is important that the receiving antenna system have no phase dispersion over the bandwidth of the signal. While this is easy to achieve for conventional signals whose bandwidth is small compared to the frequency, not all antennas have this characteristic in the case where the bandwidth is a significant fraction of the frequency. For example, a log periodic antenna has a different phase center at a different distance from the emitter for each frequency, which would result in phase dispersion for UWB signals. On the other hand, cavity-backed spiral antennas and horn antennas would be less vulnerable to this phenomenon. We seek comment on what type of measurement antennas are needed to make accurate peak measurements and the least restrictive way we might specify this in our final rules.

55. Frequency range of measurement. The comments generally agreed that the existing ranges of frequencies over which measurements are required are appropriate. LLNL suggested basing the frequency range of measurement on a function of the pulse rise time for an impulse system. For impulse systems, we believe that the center frequency of the emission bandwidth, as determined by the $10 \mathrm{~dB}$ points, should be used as the reference for determining the upper frequency range over which emissions should be measured. Noting that the emission spectrum will change depending on the specific measurement procedures employed, e.g., the use of average versus peak measurements, comments are requested on any specific measurement procedures that should be employed to determine the center frequency. For a carrier modulated system, we believe that the carrier frequency should continue to be used as the reference for determining the upper frequency range over which emissions should be measured. However, we are concerned that a manufacturer could employ a low frequency carrier with an extremely narrow pulse or a narrow pulse impulse system could be used with a low frequency antenna, resulting in emissions extending far beyond the tenth harmonic, the normal upper range of measurement. Accordingly, comments are requested on whether a different method of determining the frequency measurement range should be employed, e.g., a system based on pulse rise time and width. In addition, commenting parties should note that the lower frequency range of measurements would continue to be determined by the lowest radio frequency generated in the device. Comments are requested on whether the pulse repetition frequency, pulse dithering frequency, modulating frequency or other factors would permit the investigation of a low enough frequency range to address possible amplification of the emitted signal due to antenna resonances below the fundamental emission.

\section{Prohibition Against Class B, Damped Wave Emissions}

56. In the NOI, the Commission noted that the rules prohibit the use of Class B, damped wave emissions. This prohibition stems from a similar International Telecommunication Union regulation and is a throwback to the days when spark gap transmitters were employed. There is no longer a clear definition of a Class $B$, damped wave emission. In the NOI, the Commission questioned whether the prohibition against damped wave emissions should apply to UWB systems or if the prohibition was relevant in light of the relatively low power levels employed by UWB devices. 
57. Except for MSSI, all of the comments agreed that we should eliminate the prohibition against Class B, damped wave emissions as this does not appear to be relevant at the power levels being proposed for UWB transmissions. We agree. These levels appear to be low enough to prevent harmful interference to other users of the spectrum. Further, unlike conventional damped wave transmissions it is likely that the receivers associated with UWB transmitters would attempt to recover as much of the transmitted bandwidth as possible for information processing purposes. Accordingly, we propose to eliminate this prohibition for UWB transmitters, and seek further comment on this proposal.

\section{Other Matters}

58. Several proponents of UWB devices have questioned whether such devices can operate under the standards contained in 47 C.F.R. 15.217-15.255. This would result in a transmitter that may have a fundamental emission bandwidth greater than one gigahertz operating under the standards developed for a narrowband signal, e.g., the $30 \mathrm{MHz}$ available for radar systems operating at $5800 \mathrm{MHz}$ under 47 C.F.R. 15.245. These requests were submitted in an attempt to permit the manufacturers to avail themselves of the higher power levels permitted under these rule sections. However, in this Notice we are proposing specific regulations regarding the frequency of operation and emission levels that would apply to UWB devices. We believe that the existing rules should be amended to clarify that they do not apply to UWB devices. Accordingly, we propose to amend 47 C.F.R. 15.215(c) to state that intentional radiators operated under the provisions of 47 C.F.R. 15.217-15.255 or Subpart $E$ of the current regulations must be designed to ensure that the main lobe or the necessary bandwidth, whichever is less, is contained within the frequency bands designated in those rule section under which the equipment is operated. The requirement to contain the fundamental emission within one of the specified frequency bands would include the effects from frequency sweeping, frequency hopping and other modulation techniques that may be employed as well as the frequency stability of the transmission over variations in temperature and supply voltage. If a frequency stability is not specified, the regulation would continue to recommend that the fundamental emission be kept within at least the central 80 percent of the band in order to minimize the possibility of out-of-band operation.

59. We propose to require that the regulations proposed in this Notice become effective 60 days from the date of publication of the Report and Order in this proceeding in the Federal Register. Comments are requested on this proposed transition provision.

\section{PROCEDURAL MATTERS}

60. As required by Section 603 of the Regulatory Flexibility Act, 5 U.S.C. 603, the Commission has prepared an Initial Regulatory Flexibility Analysis (IRFA) of the expected impact on small entities of the proposals suggested in this document. The IRFA is set forth in Appendix A. Written public comments are requested on the IRFA. These comments must be filed in accordance with the same filing deadlines as comments on the rest of the Notice of Proposed Rule Making ("Notice"), but they must have a separate and distinct heading designating them as responses to the IRFA. The Commission's Consumer Information Bureau, Reference Information Center, SHALL SEND a copy of this Notice, including the IRFA, to the Chief Counsel for Advocacy of the Small Business Administration in accordance with Section 603(a) of the Regulatory Flexibility Act, 5 U.S.C. 603(a).

61. This is a permit-but-disclose notice and comment rule making proceeding. Ex parte presentations are permitted, except during the Sunshine Agenda period, provided they are disclosed as provided in the Commission's rules. See generally 47 C.F.R. 1.1202, 1.1203, and 1.2306(a).

62. Pursuant to Sections 1.415 and 1.419 of the Commission's Rules, 47 C.F.R. 1.415 and 1.419, interested parties may file comments on or before [insert date 90 days from date of publication in the Federal Register] and reply comments on or before [insert date 120 days from date of publication in the Federal Register]. Comments may be filed using the Commission's Electronic Comment Filing System (ECFS), http://www.fcc.gov/e-file/ecfs.html, or by filing paper copies. See Electronic Filing of Documents in Rulemaking Proceedings, 63 Fed. Reg. 23,121 (1998).

63. Comments filed through the ECFS can be sent as an electronic file via the Internet to http://www.fcc.gov/e-file/ecfs.html. Generally, only one copy of an electronic submission must be filed. If 
multiple docket or rule making numbers appear in the caption of this proceeding, however, commenters must transmit one electronic copy of the comments to each docket or rule making number referenced in the caption.

In completing the transmittal screen, commenters should include their full name, Postal Service mailing address, and the applicable docket or rule making number. Parties may also submit an electronic comment by

Internet e-mail. To get filing instructions for e-mail comments, commenters should send an e-mail to ecfs@fcc.gov, and should including the following words in the body of the message, "get form <your e-mail address." A sample form and directions will be sent in reply.

64. Parties who choose to file by paper must file an original and four copies of each filing. If more than one docket or rule making number appear in the caption of this proceeding, commenters must submit two

additional copies for each additional docket or rule making number. All filings must be sent to the Commission's Secretary, Magalie Roman Salas, Office of the Secretary, Federal Communications Commission, 445 12th Street, S.W., TW-A325, Washington, D.C. 20554. Comments and reply comments will be available for public inspection during regular business hours in the FCC Reference Center of the Federal Communications Commission, Room TW-A306, 445 12th Street, S.W., Washington, D.C. 20554.

65. The proposed action is authorized under Sections 4(i), 301, 302, 303(e), 303(f), 303(r), 304 and 307 of the Communications Act of 1934, as amended, 47 USC Sections 154(i), 301, 302, 303(e), 303(f), 303(r), 304, and 307.

66. To make cited sources more easily available to the readers, we are testing the use of hyperlinks to some FCC documents that are cited in this document. The World Wide Web addresses/URLs that we give here were correct at the time this document was prepared but may change over time. We do not have dedicated staff to update these URLs, however, so readers may find some URLs to be out of date as time progresses. We also advise that the only definitive text of FCC documents is the one that is published in the FCC Record. In case of discrepancy between the electronic documents cited here and the FCC Record, the version in the FCC Record is definitive.

67. For further information regarding this Notice of Proposed Rule Making, contact John A. Reed, Office of Engineering and Technology, (202) 418-2455.

FEDERAL COMMUNICATIONS COMMISSION

\author{
Magalie Roman Salas \\ Secretary \\ APPENDIX A
}

Initial Regulatory Flexibility Analysis

As required by Section 603 of the Regulatory Flexibility Act, the Commission has prepared an Initial Regulatory Flexibility Analysis (IRFA) of the expected significant economic impact on small entities by the policies and rules proposed in this Notice of Proposed Rule Making ("Notice"). Written public comments are requested on the IRFA. Comments must be identified as responses to the IRFA and must be filed by the deadlines for comments on the Notice provided above. The Commission shall send a copy of this

Notice, including the IRFA, to the Chief Counsel for Advocacy of the Small Business Administration in accordance with paragraph 603(a) of the Regulatory Flexibility Act.

\title{
A. Reason for Action.
}

This rule making proposal is initiated to obtain comments regarding proposed changes to the regulations for radio frequency devices that do not require a license to operate. The Commission seeks to 
determine if its standards should be amended to permit the operation of ultra-wideband transmission systems.

\title{
B. Legal Basis.
}

The proposed action is taken pursuant to Sections 4(i), 301, 302, 303(e), 303(f), 303(r), 304 and 307 of the Communications Act 10 1934, as amended, 47 U.S.C. Sections 154(i), 301, 302, 303(e), 303(f), 303(r), 304 , and 307.

C. Description and Estimate of the Number of Small Entities to Which the Proposed Rules Will Apply.

For the purposes of this Notice, the RFA defines a "small business" to be the same as a "small business concern" under the Small Business Act, 15 U.S.C. 632, unless the Commission has developed one or more definitions that are appropriate to its activities. Under the Small Business Act, a "small business concern" is one that: (1) is independently owned and operated; (2) is not dominant in its field of operations; and (3) meets any additional criteria established by the Small Business Administration (SBA). SBA has defined a small business for Standard Industrial Classification (SIC) category 4812 (Radiotelephone Communications) to be small entities when they have fewer than 1500 employees. Given this definition, nearly all such companies are considered small.

\section{Description of Projected Reporting, Recordkeeping and Other Compliance Requirements.}

Part 15 transmitters are already required to be authorized under the Commission's certification procedure as a prerequisite to marketing and importation. The reporting and recordkeeping requirements associated with these equipment authorizations would not be changed by the proposals contained in this Notice. These changes to the regulations would permit the introduction of an entirely new category of radio transmitters.

E. Significant Alternatives to Proposed Rules Which Minimize Significant Economic Impact on Small Entities and Accomplish Stated Objectives.

We do not expect that the rules proposed in this Notice of Proposed Rule Making will have a significant negative impact on small businesses.

F. Federal Rules that May Duplicate, Overlap, or Conflict with the Proposed Rule.

None.

\author{
APPENDIX B \\ Commenting Parties
}

Parties filing comments:

1. American Radio Relay League, Inc. (ARRL)

2. ANRO Engineering, Inc.

3. Arthur D. Little Inc. (ADL)

4. Dwain K. Butler, U. S. Army Corps of Engineers

5. Chesapeake Computer Consultants, Inc.

6. Consumer Electronics Manufacturers Association (CEMA) and National Association of

Broadcasters (NAB) - joint filing

7. Endress + Hauser GmbH \& Co. (Endress Hauser)

8. Geophysical Survey Systems, Inc. (GSSI)

9. David R. Hughes, Principal Investigator, National Science Foundation Wireless Field Test

Project (corrected copy)

10. Interval Research Corporation (Interval)

11. George L. Johnston

12. Jeff Kramer 
13. Lawrence Livermore National Laboratory, U.S. Department of Energy (LLNL)

14. Low Tech Designs, Inc. (LTD)

15. M/A-Com

16. Magnetrol International

17. MALA GeoScience USA, Inc.

18. Multispectral Solutions, Inc. (MSSI)

19. NeoVac

20. Gary R. Olhoeft

21. Pulson Medical, Inc. (PMI)

22. Quality Research

23. Radar Solutions International

24. Rosemount Measurement

25. SAAB Marine Electronics

26. SAT COM Consultants, Inc.

27. Robert $A$. Scholtz

28. Enrico M. Staderine

29. Technos Inc.

30. TEM Innovations

31. Time Domain Corporation (Time Domain or TDC)

32. TRW Electronics \& Technology Division

33. UltraPulse Communications, Inc. (UCI) (2 comments)

34. Ultra-Wideband Working Group (UWBWG)

35. U.S. Department of Transportation, Federal Aviation Administration

36. U.S. Geological Survey

37. U.S. GPS Industry Council (Council)

38. U.S. Radar Inc.

39. Kathryn Vestal

40. Wireless Information Networks Forum (WINForum)

41. XtremeSpectrum, Inc.

42. Zircon Corporation (Zircon)

Parties filing reply comments:

1. American Radio Relay League, Inc. (ARRL)

2. Arthur D Little Inc. (ADL)

3. Broadband Telecom Systems

4. Janice Bradley, Director, Lewistown Public Library

5. Frank Burns

6. California Geophysical Group, Inc.

7. Barbara Dean Clark

8. Thomas N. Cokenias

9. Community Technology Centers' Network

10. ENSCO, Inc.

11. Geo-Recovery Systems, Inc.

12. E. Renee Gross, Sidney Public Library

13. Clifford Harter

14. David R. Hughes

15. Interval Research Corporation (Interval)

16. Robert W. Jacob

17. Krohne, Inc.

18. M/A-COM

19. Milltronics

20. Oak Ridge National Laboratory

21. Jim Rezowalli

22. Rosemount Inc.

23. Saab Marine Electronics (Saab)

24. Timothy J. Shepard

25. Southwestern Bell Wireless, Inc.

26. SPARTA, Inc., Simulation Technology Division 
27. Sub-Surface Informational Surveys, Inc.

28. TEM Innovations (2 replies)

29. Time Domain Corporation

30. Kathryn Vestal

31. XtremeSpectrum, Inc.

32. Ultra-Wideband Working Group

33. U.S. GPS Industry Council, American Airlines, The General Aviation Manufacturers Association, Stanford University (The GPS Research Program) and United Airlines

34. John A. Williams

35. Bonnie Williamson, Havre-Hill County Library

36. Zircon Corporation

37. Brian Zisk 